\title{
EASE Guidelines for Authors and
}

\section{Translators of Scientific Articles}

\section{to be Published in English}

November 2018

\section{European}

\section{Association of}

\section{Science}

\section{Editors}

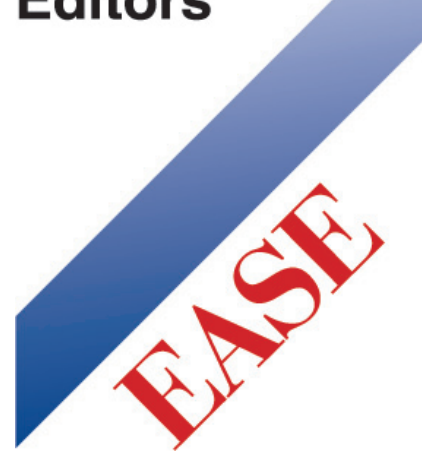

e2 Guidelines

e7 Appendix: Abstracts

e8 Appendix: Ambiguity

e9 Appendix: Cohesion

e10 Appendix: Ethics

e11 Appendix: Plurals

e12 Appendix: Simplicity

e13 Appendix: Spelling

e14 Appendix:Text-tables

e14 Practical tips for junior researchers

e15 About EASE
Updated annually, freely available in many languages at www.ease.org.uk 


\section{EASE Guidelines for Authors and Translators of Scientific Articles to be Published in English}

DOI:10.20316/ESE.2018.44.e1

\begin{abstract}
This concise and readable set of editorial guidelines was first published by the European Association of Science Editors (EASE) in 2010 and is updated annually. It is freely available in more than 20 languages at http://ease.org.uk/ publications/author-guidelines. The document is aimed to help scientists worldwide in successful presentation of their research results and in correct translation of manuscripts into English. It briefly explains how to write complete, concise, and clear manuscripts, and draws attention to ethical issues: authorship criteria, plagiarism, conflict of interests, etc. Eight appendices provide examples or more detailed information on selected topics (Abstracts, Ambiguity, Cohesion, Ethics, Plurals, Simplicity, Spelling, and Text-tables). Widespread use of EASE Guidelines should increase the efficiency of international scientific communication.
\end{abstract}

To make international scientific communication more efficient, research articles and other scientific publications should be COMPLETE, CONCISE, and CLEAR, as explained below. These are generalized but not universal guidelines, intended to help authors, translators, and editors. Common sense is necessary when applying these rules, as perfection is impossible to reach.

First of all:

- Carefully plan and conduct your study (eg Hengl et al 2011). Do not begin drafting the whole paper until you are sure that your findings are reasonably firm and complete (O'Connor 1991), allowing you to draw reliable conclusions.

- Before you start writing, preferably choose the journal to which you will submit your manuscript. Make sure that the journal's readership corresponds to your target audience (Chipperfield et al 2010). Get a copy of the journal's instructions to authors and plan the article to fit the journal's preferred format in terms of overall length, number of figures required/allowed, etc.

Manuscripts should be COMPLETE, ie no necessary information should be missing. Remember that information is interpreted more easily if it is placed where readers expect to find it (Gopen \& Swan 1990). For example, the following information ought to be included in experimental research articles.

- Title: should be unambiguous, understandable to specialists in other fields, and reflect the content of the article. Be specific, not general or vague (O'Connor 1991). If relevant, mention in the title the study period and location, the international scientific name of the studied organism or the experimental design (eg case study or randomized controlled trial). If your study included human subjects of one sex, it should be stated in the title. Information given in the title does not need to be repeated in the abstract (as they are always published jointly), although overlap is unavoidable.

- List of authors, ie all people who contributed substantially to study planning, data collection or interpretation of results and wrote or critically revised the manuscript and approved its final version and agree to be accountable for all aspects of the work. Each person who meets the first criterion should be allowed to participate in the drafting and approval of the final version (ICMJE 2017). The authors listed first should be those who did most. The name order of authors should be determined before submission of the manuscript. Any changes made after submission should be approved by all authors and explained to the journal editor (Battisti et al 2015, see COPE flowcharts). Names of authors must be supplemented with their affiliations (during the study) and the present address of an author for correspondence. Email addresses of all authors should be provided, so that they can be contacted easily. We also encourage all authors to sign up for an ORCiD id - a unique author identifier that links you with your articles (http://www.orcid.org).

- Abstract: briefly explain why you conducted the study (BACKGROUND), what question(s) you aimed to answer (OBJECTIVES), how you performed the study (METHODS), what you found (RESULTS: major data, relationships), and your interpretation and main consequences of your findings (CONCLUSIONS). The abstract must reflect the content of the article, as for most readers it will be the major source of information about your study. You must use keywords within the abstract, to facilitate on-line searching for your article by those who may be interested in your results (many databases include only titles and abstracts). In a research report, the abstract should be informative, including actual results. (See Appendix: Abstracts about structured abstracts.) Only in reviews and other widescope articles, should the abstract be indicative, ie listing the major topics discussed but not giving outcomes (CSE 2014). Do not refer in the abstract to tables or figures, as abstracts are also published separately. References to the literature are also not allowed unless they are absolutely necessary (but then you need to provide detailed information in brackets: author, title, year, etc.). Make sure that all the information given in the abstract also appears in the main body of the article.

- List of keywords: include all relevant scientific terms or only additional keywords that are absent from the title (if required by the editors). Keep the keywords specific. Add more general terms if your study has interdisciplinary significance (O’Connor 1991). In 
medical texts, use vocabulary found in the MeSH Browser. When archiving your article in repositories, etc. (Cerejo 2013), embed all keywords and other metadata in the file (eg see Inderscience 2013).

- List of abbreviations (if required by the editors): define all abbreviations used in the article, except those obvious to non-specialists.

- Introduction: explain why the study was needed and specify your research objectives or the question(s) you aimed to answer. Start from more general issues and gradually focus on your research question(s). If possible, formulate the hypothesis you tested.

- Methods: describe in detail how the study was carried out (eg study area, data collection, criteria, origin of analysed material, sample size, number of measurements, age and sex of participants or tissue/cell donors, equipment, data analysis, statistical tests, and software used). All factors that could have affected the results need to be considered. Sources of experimental materials obtained from biobanks should be mentioned with full names and identifiers, if available (Bravo et al 2015). If you cite a method described in a non-English or inaccessible publication, explain it in detail in your manuscript. Make sure that you comply with the ethical standards (eg WMA 2013) in respect of patient rights, animal testing, environmental protection, etc.

- Results: present the new results of your study (usually published data should not be included in this section). All tables and figures must be mentioned in the main body of the article, and numbered in the order in which they appear in the text. Make sure that the statistical analysis is appropriate (eg Habibzadeh 2013). Data on humans, animals or any material originating from humans or animals, should be disaggregated by sex (see Heidari et al 2016). Do not fabricate or distort any data, and do not exclude any important data; similarly, do not manipulate images to make a false impression on readers. Such data manipulations may constitute scientific fraud (see COPE flowcharts).

- Discussion: this section is not the place to present new results, including statistical results. Answer your research questions (stated at the end of the Introduction) and compare your main results with published data, as objectively as possible. Discuss their limitations and highlight your main findings. If your study included subjects of one sex, discuss the implications and potential to generalize your findings for both sexes. Consider any findings that run contrary to your point of view. To support your position, use only methodologically sound evidence (Roig 2015). At the end of the Discussion or in a separate section, emphasize your major conclusions and the practical significance of your study.

- Acknowledgements: mention all people who contributed substantially to the study but cannot be regarded as co-authors, and acknowledge all sources of funding. The recommended form is: "This work was supported by the Medical Research Council [grant number $\mathrm{xxxx}$ ]". If no specific funding was provided, use the following sentence: "This research received no specific grant from any funding agency in the public, commercial, or not-for-profit sectors." (RIN 2008). If relevant, disclose to the editors any other conflicts of interest, eg financial or personal links with the manufacturer or with an organization that has an interest in the submitted manuscript (Goozner et al 2009). If you reproduce previously published materials (eg figures), ask the copyright owners for permission and mention them in the captions or in the acknowledgements. If you were helped by a language professional (eg author's editor or translator), a statistician, data collectors, etc., you should acknowledge their assistance for the sake of transparency (ICMJE 2017, Battisti et al 2015). It must be clear that they are not responsible for the final version of the article. You need to ensure you have the consent of all the people named in this section. (See Appendix: Ethics)

- References: make sure that you have provided sources for all information extracted from other publications. In the list of references, include all data necessary to find them in a library or in the Internet. For non-English publications, give the original title (transliterated according to English rules if necessary), wherever possible followed by its translation into English in square brackets (CSE 2014). Avoid citing inaccessible, coercive and irrelevant references. Wherever appropriate, cite primary research articles instead of reviews (DORA 2013). Do not include unpublished data in the list of references - if you must mention them, describe their source in the main body of the article, and obtain permission from the producer of the data to cite them.

- A different article structure may be more suitable for theoretical publications, review articles, case studies, etc (eg Gasparyan et al 2011).

- Some publications include also an abstract or a longer summary in another language. This is very useful in many fields of research.

- Following reporting guidelines will help you to provide minimum necessary information about your study (see eg EQUATOR Network).

- Remember to comply with the journal's instructions to authors in respect of abstract length, style of references, etc.

Write CONCISELY to save the time of referees and readers.

- Do not include information that is not relevant to your research question(s) stated in the Introduction.

- Do not copy parts of your previous publications and do not submit the same manuscript to more than one journal at a time. Otherwise, you may be responsible for redundant publication (see COPE flowcharts). This does not apply to preliminary publications, such as conference abstracts (O'Connor 1991, see also BioMed Central policy). Moreover, secondary publications are 
acceptable if intended for a completely different group of readers (eg in another language or for specialists and the general public) and you have received approval from the editors of both journals (ICMJE 2017). A reference to the primary publication must then be given in a footnote on the title page of the secondary publication.

- Information given in one section preferably should not be repeated in other sections. Obvious exceptions include the abstract, the figure legends, and the concluding paragraph.

- Consider whether all tables and figures are necessary. Data presented in tables should not be repeated in figures (or vice versa). Long lists of data should not be repeated in the text.

- Captions to tables and figures must be informative but not very long. If similar data are presented in several tables or several figures, then the format of their captions should also be similar.

- Preferably delete obvious statements (eg "Forests are very important ecosystems.") and other redundant fragments (eg "It is well known that...").

- If a long scientific term is frequently repeated, define its abbreviation at first use in the main body of the article, and later apply it consistently.

- Express your doubts if necessary but avoid excessive hedging (eg write "are potential" rather than "may possibly be potential"). However, do not overgeneralize your conclusions.

- Unless required otherwise by the editors, use numerals for all numbers, ie also for one-digit whole numbers, except for zero, one (if without units), and other cases where misunderstanding is possible, eg at the beginning of a sentence or before abbreviations containing numbers (CSE 2014).

Write CLEARLY to facilitate understanding - make the text readable.

\section{Scientific content}

- Clearly distinguish your original data and ideas from those of other people and from your earlier publications - provide citations whenever relevant. Preferably summarize or paraphrase text from other sources. This applies also to translations. When copying text literally (eg a whole sentence or longer text), put it in quotation marks (eg Roig 2015, Kerans \& de Jager 2010). Otherwise you could commit plagiarism or content recycling (unjustified, excessive recycling of text, data, illustrations, etc. or even redundant publication, see COPE flowcharts and COPE guidelines).

- Make sure that you are using proper English scientific terms, preferably on the basis of texts written by native English speakers. Literal translations are often wrong (eg so-called false friends or non-existent words invented by translators). If in doubt, check the definition in an English dictionary, as many words are used incorrectly (eg gender and trimester; see Appendix: Ambiguity). You can also search for a word or phrase in Wikipedia, for example; then compare the results in your native language and in English, and see if the meaning of putative equivalents is truly the same. However, Wikipedia is not always a reliable source of information.

- If a word is used mostly in translations and only rarely in English-speaking countries, consider replacing it with a commonly known English term with a similar meaning (eg plant community instead of phytocoenosis). If a scientific term has no synonym in English, then define it precisely and suggest an acceptable English translation.

- Define every uncommon or ambiguous scientific term at first use. You can list its synonyms, if there are any (to aid in searching), but later employ only one of them consistently (to prevent confusion). Formal nomenclature established by scientific organisations should be preferred (eg EASE 2013).

- Avoid unclear statements, which require the reader to guess what you meant. (See Appendix: Ambiguity)

- When reporting percentages, make clear what you regard as $100 \%$. When writing about correlations, relationships, etc., make clear which values you are comparing with which.

- Système International (SI) units and Celsius degrees are generally preferred.

- Unlike many other languages, English has a decimal point (not comma). Unless required otherwise by the editors, in numbers exceeding 4 digits to the right or left of the decimal point, use thin spaces (not commas) between groups of 3 digits in either direction from the decimal point (EASE 2013).

- To denote centuries, months, etc., do not use capital Roman numerals, as they are rare in English. Because of differences between British and American date notation (see below), preferably denote months as whole words or their first 3 letters (CSE 2014).

- If lesser known geographic names are translated, the original name should also be mentioned if possible, eg "in the Kampinos Forest (Puszcza Kampinoska)". Some additional information about location, climate, etc., may also be useful for readers.

- Remember that the text will be read mainly by foreigners, who may be unaware of the specific conditions, classifications or concepts that are widely known in your country; therefore, addition of some explanations may be necessary (Ufnalska 2008). For example, the common weed Erigeron annuus is called Stenactis annua in some countries, so in English texts the internationally approved name should be used, while its synonym(s) should be added in brackets.

\section{Text structure}

- Sentences generally should not be very long. Their structure should be relatively simple, with the subject located close to its verb (Gopen \& Swan 1990). For example, avoid abstract nouns and write "X was 
measured..." instead of "Measurements of X were carried out..." (See Appendix: Simplicity) Do not overuse passive constructions (eg Norris 2011). When translating, modify sentence structure if necessary to convey the message correctly or more clearly (BurroughBoenisch 2013).

- The text should be cohesive, logically organised, and thus easy to follow. (See Appendix: Cohesion)

- Each paragraph preferably should start with a topic sentence, and the next sentences fully develop the topic.

- In contrast to some other languages, English allows parallel constructions, as they facilitate understanding. For example, when comparing similar data, you can write "It was high in A, medium in B, and low in C", rather than "It was high in $\mathrm{A}$, medium for $\mathrm{B}$, and low in the case of C".

- Make figures and tables easily understandable without reference to the main body of the article. Omit data that are not informative (eg delete a column if it contains the same values in all rows - you can write about it in a footnote instead). Apply abbreviations only if necessary for consistency or if there is not enough room for whole words. In captions or footnotes, define all abbreviations and symbols that are not obvious (eg error bars may denote standard deviation, standard error or confidence intervals). Remember to use decimal points (not decimal commas) and provide axis labels and units wherever needed.

- Consider using a text-table when presenting a small set of data (Kozak 2009). (See Appendix: Text-tables)

- In long lists (of abbreviations, etc.), preferably separate individual items by semicolons (;), which are intermediate between commas and full stops.

\section{Language matters}

- Wherever scientific terms are not necessary, preferably use commonly known words. However, avoid colloquial and idiomatic expressions, as well as phrasal verbs, (eg find out, pay off), which are often difficult to understand by non-native speakers of English (Geercken 2006).

- Define abbreviations when they first appear in the main body of the article (if they may be unclear to readers). Do not use too many different abbreviations, as the text would be hard to understand. Do not abbreviate terms that are used only rarely in your manuscript. Avoid abbreviations in the abstract.

- In general, use the past tense when describing how you performed your study and what you found or what other researchers did. Preferably use the present tense in general statements and interpretations (eg statistical significance, conclusions) or when writing about the content of your article, especially tables and figures (Gastel \& Day 2016).

- Unless required otherwise by the editors, do not write about yourself "the author(s)", as this is ambiguous. Instead, write "we" or "I" if necessary, or use expressions like "in this study", "our results" or "in our opinion" (eg
Hartley 2010, Norris 2011). Note that you should write "this study" only if you mean your new results. If you mean a publication mentioned in a previous sentence, write "that study". If you mean authors of a cited publication, write "those authors".

- Remember that in scientific texts the word "which" should be used in non-defining clauses, while "that" in defining clauses (ie meaning "only those that").

- When using equivocal words, make sure that their meaning is obvious from the text context. Check if all verbs agree in number with their subjects and if the references for all pronouns are clear (this is crucial in translated texts). Note that some nouns have irregular plurals. (See Appendix: Plurals)

- Read the text aloud to check punctuation. All intonation breaks necessary for proper understanding should be denoted with commas or other punctuation marks (eg note the difference between "no more data are needed" and "no, more data are needed").

- Be consistent in spelling. Follow either British or American rules for spelling and date notation (eg "21 Jan 2009" in British, or "Jan 21, 2009" in American English; see Appendix: Spelling). Check whether the target journal uses American or British spelling, and then use that setting on your word and grammar check.

- Ask a thoughtful colleague to read the whole text, to see if there are any ambiguous fragments.

CONTRIBUTORS TO THE GUIDELINES (in chronological order): Sylwia Ufnalska (initiator and editor, sylwia.ufnalska@ gmail.com), Paola De Castro, Liz Wager, Carol Norris, James Hartley, Françoise Salager-Meyer, Marcin Kozak, Ed Hull, Angela Turner, Will Hughes, Peter Hovenkamp, Thomas Babor, Eric Lichtfouse, Richard Hurley, Mercè Piqueras, Maria Persson, Elisabetta Poltronieri, Suzanne Lapstun, Mare-Anne Laane, David Vaux, Arjan Polderman, Ana Marusic, Elisabeth Heseltine, Joy Burrough-Boenisch, Eva Baranyiová, Tom Lang, Arie Manten, Pippa Smart, Armen Gasparyan, John Miescher, Shirin Heidari, Ksenija Baždarić

\section{References and further reading}

AuthorAID Resource Library. http://www.authoraid.info/ resource-library

Baranyiová E. 2013 . Correct terminology in science: the role of editors. Science Editor 36 (2): 63. http://www. councilscienceeditors.org/wp-content/uploads/v36n2p63.pdf

Battisti WP, Wager E, Baltzer L, Bridges D, Cairns A, Carswell CI, et al 2015. Good publication practice for communicating company-sponsored medical research: GPP3. Ann Intern Med. https://doi.org/10.7326/M15-0288

Beverley P. 2015. Word macros for writers and editors. http:// www.archivepub.co.uk/TheBook

BioMed Central policy on duplicate publication. https://www.biomedcentral.com/getpublished/ editorial-policies\#duplicate+publication

Bravo E, Calzolari A, De Castro P, Mabile L, Napolitani F, Rossi AM, Cambon-Thomsen A. 2015. Developing a guideline to standardize the citation of bioresources in journal articles 
(CoBRA). BMC Medicine 13:33. https://doi.org/10.1186/ s12916-015-0266-y

Burrough-Boenisch J. 2013. Editing texts by non-native speakers of English. In: European Association of Science Editors. Science editors' handbook. Smart P, Maisonneuve H, Polderman A. http://www.ease.org.uk/publications/ science-editors-handbook/

Cerejo C. 2013. How to make your paper more accessible through self-archiving. Editage Insights. http://www.editage. com/insights/how-to-make-your-paper-more-accessiblethrough-self-archiving

Chipperfield L, Citrome L, Clark J, David FS, Enck R, Evangelista $\mathrm{M}$, et al 2010. Authors' Submission Toolkit: a practical guide to getting your research published. Current Medical Research \& Opinion 26(8):1967-1982. https://doi.org/10.1185/0300799 5.2010 .499344

[COPE flowcharts] Committee on Publication Ethics flowcharts. http://publicationethics.org/resources/flowcharts

[COPE guidelines] Committee on Publication Ethics. Text recycling guidelines for editors https://publicationethics.org/ files/Web_A29298_COPE_Text_Recycling.pdf

[CSE] Council of Science Editors, Style Manual Committee. 2014. Scientific style and format: the CSE manual for authors, editors, and publishers. 8th ed. Univeristy of Chicago Press. http://www.scientificstyleandformat.org/Home.html

[DORA] San Francisco Declaration on Research Assessment. 2013. http://www.ascb.org/dora/

[EASE] European Association of Science Editors. 2012. EASE Toolkit for Authors. http://www.ease.org.uk/publications/ ease-toolkit-authors

[EASE] European Association of Science Editors. 2013. Science editors' handbook. 2nd ed. Smart P, Maisonneuve H, Polderman A, editors. http://www.ease.org.uk/publications/ science-editors-handbook/

EQUATOR Network. http://www.equator-network.org/

Gasparyan AY, Ayvazyan L, Blackmore H, Kitas GD. 2011. Writing a narrative biomedical review: considerations for authors, peer reviewers, and editors. Rheumatology International 31(11):1409-1417. https://doi.org/10.1007/ s00296-011-1999-3

Gastel B, Day RA. 2016. How to write and publish a scientific paper, 8th edition. Santa Barbara: ABC-CLIO

Geercken S. 2006. Challenges of (medical) writing for the multilingual audience. Write Stuff 15(2):45-46. http://journal. emwa.org/documents/journal/TWS/TWS\%202006\%20 2\%2015.pdf

Goozner M, Caplan A, Moreno J, Kramer BS, Babor TF, Husser WC. 2009. A common standard for conflict of interest disclosure in addiction journals. Addiction 104:1779-1784. https://doi.org/10.1111/j.1360-0443.2009.02594.x

Gopen GD, Swan JA. 1990. The science of scientific writing: if the reader is to grasp what the writer means, the writer must understand what the reader needs. American Scientist 78(6):550-558. https://www.americanscientist.org/blog/ the-long-view/the-science-of-scientific-writing

Habibzadeh F. 2013. Common statistical mistakes in manuscripts submitted to biomedical journals. European Science Editing 39(4):92-94. http://europeanscienceediting.eu/issues/394/
Hartley J. 2010. Citing oneself. European Science Editing 36(2):3537. http://www.ease.org.uk/sites/default/files/may_2010_362. pdf

Heidari S, Babor TF, De Castro P, Tort S, Curno M. 2016. Sex and Gender Equity in Research: rationale for the SAGER guidelines and recommended use. Research Integrity and Peer Review 1:2. https://doi.org/10.1186/s41073-016-0007-6

Hengl T, Gould M, Gerritsma W. 2012. The unofficial guide for authors: from research design to publication. Wageningen, Arnhem. http://www.lulu.com/spotlight/t_hengl

Hull E. 2015. Health-related scientific articles in the 21st century: give readers nuggets! Vught, Netherlands: Professional English. https://www.givereadersnuggets.nl/

[ICMJE] International Committee of Medical Journal Editors. 2017. Recommendations for the Conduct, Reporting, Editing, and Publication of Scholarly Work in Medical Journals. http:// www.icmje.org/urm_main.html

[Inderscience] Inderscience Publishers. 2013. Keyword requirements. http://www.inderscience.com/info/insitemap. php

Kerans ME, de Jager M. 2010. Handling plagiarism at the editor's desk. European Science Editing 36(3): 62-66. http://www.ease. org.uk/sites/default/files/ese_aug10.pdf

Kozak M. 2009. Text-table: an underused and undervalued tool for communicating information. European Science Editing 35(4):103. http://www.ease.org.uk/sites/default/files/ november_2009_354.pdf_

Marusic M. 2014. Gender and sex in medical research. European Science Editing 40(2):56. http://www.ease.org.uk/sites/default/ files/corresp_2.pdf

[MeSH Browser] Medical Subject Headings Browser. http://www. nlm.nih.gov/mesh/MBrowser.html

Norris C. 2011. The passive voice revisited. European Science Editing 37(1):6-7. http://www.ease.org.uk/sites/default/files/ february_2011_371.pdf

O'Connor M. 1991. Writing successfully in science. London: Chapman \& Hall.

Research Methods Supercourse. http://www.pitt.edu/ super1/ ResearchMethods/index.htm

[RIN] Research Information Network. 2008. Acknowledgement of funders in journal articles. http://www.rin.ac.uk/system/ files/attachments/Acknowledgement-funders-guidance.pdf

Roig M. 2015. Avoiding plagiarism, self-plagiarism, and other questionable writing practices: a guide to ethical writing. Office of Research Integrity http://ori.hhs.gov/education/products/ plagiarism/0.shtml

Seifert KA, Crous PW, Frisvad JC. 2008. Correcting the impact factors of taxonomic journals by Appropriate Citation of Taxonomy (ACT). Persoonia 20:105. https://doi. org/10.3767/003158508X324236

Ufnalska S. 2008. Abstracts of research articles: readers' expectations and guidelines for authors. European Science Editing 34(3):63-65. http://www.ease.org.uk/sites/default/files/august_2008343.pdf

[WMA] World Medical Association. 2013. Declaration of Helsinki - ethical principles for medical research involving human subjects. https://www.wma.net/wp-content/uploads/2016/11/DoHOct2013-JAMA.pdf 


\section{Key elements of abstracts}

Researchers are quite often in a "box" of technical details - the "important" things they focus on day in and day out. As a result, they frequently lose sight of 4 items essential for any readable, credible, and relevant $\mathrm{IMRaD}^{1}$ article: the point of the research, the research question, its answer, and the consequences of the study.

To help researchers to get out of the box, I ask them to include 5 key elements in their research report and in their abstract. I describe briefly the elements below and illustrate them with a fictitious abstract.

Key element 1 (BACKGROUND): the point of the research - why should we care about the study? This is usually a statement of the BIG problem that the research helps to solve and the strategy for helping to solve it. It prepares the reader to understand the specific research question.

Key element 2 (OBJECTIVES): the specific research question - the basis of credible science. To be clear, complete and concise, research questions are stated in terms of relationships between the variables that were investigated. Such specific research questions tie the story together they focus on credible science.

Key element 3 (METHODS): a precise description of the methods used to collect data and determine the relationships between the variables.

Key element 4 (RESULTS): the major findings - not only data, but the RELATIONSHIPS found that lead to the answer. Results should generally be reported in the past tense but the authors' interpretation of the factual findings is in the present tense - it reports the authors' belief of how the world IS. Of course, in a pilot study such as the following example, the authors cannot yet present definitive answers, which they indicate by using the words "suggest" and "may".
Key element 5 (CONCLUSIONS): the consequences of the answers - the value of the work. This element relates directly back to the big problem: how the study helps to solve the problem, and it also points to the next step in research.

Here is a fictitious structured abstract, using these headings.

\section{Predicting malaria epidemics in Ethiopia}

\section{Abstract}

BACKGROUND: Most deaths from malaria could be prevented if malaria epidemics could be predicted in local areas, allowing medical facilities to be mobilized early. OBJECTIVES: As a first step toward constructing a predictive model, we determined correlations between meteorological factors and malaria epidemics in Ethiopia. METHODS: In a retrospective study, we collected meteorological and epidemic data for 10 local areas, covering the years 1963-2006. Poisson regression was used to compare the data. RESULTS: Factors AAA, BBB, and CCC correlated significantly $(P<0.05)$ with subsequent epidemics in all 10 areas. A model based on these correlations would have a predictive power of about $30 \%$. CONCLUSIONS: Meteorological factors can be used to predict malaria epidemics. However, the predictive power of our model needs to be improved and validated in other areas.

This understandable and concise abstract forms the "skeleton" for the entire article. A final comment: This example is based on an actual research project and, at first, the author was in a "box" full of the mathematics, statistics, and computer algorithms of his predicting model. This was reflected in his first version of the abstract, where the word "malaria" never appeared.

Written by Ed Hull edhull@home.nl (for more information, see Hull 2015)

${ }^{1} \mathrm{IMRaD}$ stands for Introduction, Methods, Results and

Discussion. 


\section{Empty words and sentences}

Many English words are empty - they do not add information but require the reader to fill in information or context to be understood. The reader is forced to supply his or her own interpretation, which could be different from what you, the writer, mean.

Empty words seem to give information and uncritical readers do not notice them - that is why they work so well for marketing texts. However, empty words do not belong in articles reporting scientific research. Empty words require the reader to supply the meaning - very dangerous. Concise and clear communication requires words that convey specific meaning.

\section{Examples}

It is important that patients take their medicine.

- Note that to a physician the meaning is probably entirely different than to the sales manager of a pharmaceutical company. "Important" is one of our best-loved, but empty, words - it fits every situation.

The patient was treated for XXX.

- "Treated" is empty; we do not know what was done. One reader could assume that the patient was given a certain medicine, while another reader could assume that the patient was given a different medicine. Perhaps the patient was operated on, or sent to Switzerland for a rest cure.

The patient reacted well to the medicine.

- "Reacted well" gives us a positive piece of information, but otherwise it is empty; we do not know how the patient reacted.
The patient's blood pressure was low.

- We interpret "high/low blood pressure" to mean "higher/lower than normal", but we, the readers, have to supply that reference standard. A more concise statement is: The patient's blood pressure was 90/60.

Empty words and phrases not only require the reader to supply the meaning, they also contribute to a wordy blahblah text. In scientific articles they destroy credibility. Here are some examples.

It has been found that the secondary effects of this drug include...

- Better: The secondary effects of this drug include...(ref.). Or, if these are your new results: Our results show that the secondary effects of this drug include...

We performed a retrospective evaluation study on XXX.

- "Performed a study" is a much overused and rather empty phrase. Better: We retrospectively evaluated XXX.

More examples that require the reader to supply information if it is not evident from the context:

- quality

- $\mathrm{good} / \mathrm{bad}$

- high/low

- large/small

- long/short

- proper/properly (eg “...a proper question on the questionnaire...")

- As soon as possible...
Written by Ed Hull edhull@home.nl

\section{Incorrect use of scientific terms}

Scientific language should be exact and based on unequivocal terms. However, some terms are not always used properly. For example, trimester means 3 months (usually with reference to $1 / 3$ of human pregnancy) but is often wrongly used to describe $1 / 3$ of mostly shorter pregnancy in many animal species (Baranyiová 2013). Another nowadays frequently misused word in both human and veterinary medicine is gender (eg "examined dogs of both genders"), as it is not equivalent to biological sex. The word gender applies primarily to social and linguistic contexts. By contrast, in medicine and biology, the term sex is usually correct, because biological sex (not gender) is linked with major physiological differences (Marušić 2014). Wrong use of scientific terms can lead not only to confusion but also to serious consequences, so special care should be taken to avoid it.

Written by Eva Baranyiová ebaranyi@seznam.cz 


\section{Cohesion - the glue}

The word "cohesion" means "unity", "consistency", and "solidity". Building cohesion into your text makes life easier for your readers - they will be much more likely to read the text. Cohesion "glues" your text together, focusing the readers' attention on your main message and thereby adding credibility to your work.

Think of your text as a motorcycle chain made up of separate links, where each sentence is one link. A pile of unconnected links is worthless - it will never drive your motorcycle. Similarly, a pile of unconnected sentences is worthless - it will never drive your message home.

To build a cohesive text, you have to connect your sentences together to make longer segments we call paragraphs. A cohesive paragraph clearly focuses on its topic. You then need to connect each paragraph with the previous paragraph, thereby linking the paragraph topics. Linking paragraphs results in building cohesive sections of your article, where each section focuses on its main topic. Then, link the sections to each other and, finally, connect the end of your article to the beginning, closing the loop - now the chain will drive our motorcycle. Let's look at linking techniques.

\section{Basic guidelines for building a cohesive story:}

1. Link each sentence to the previous sentence.

2. Link each paragraph to the previous paragraph.

3. Link each section to the previous section.

4. Link the end to the beginning.

\section{Linking techniques}

Whether you want to link sentences, paragraphs, sections or the beginning to the end, use 2 basic linking techniques:
- Use linking words and phrases, such as: however, although, those, since then... An example: Our research results conflict with those of Smith and Jones. To resolve those differences we measured ...

- Repeat key words and phrases - do not use synonyms. In scientific writing, repetition sharpens the focus. Repetition especially helps the reader to connect ideas that are physically separated in your text. For example: Other investigators have shown that microbial activity can cause immobilization of labile soil phosphorus. Our results suggest that, indeed, microbial activity immobilizes the labile soil phosphorus.

The example below illustrates how to link your answer to your research question, thus linking the Discussion with the Introduction.

In the Introduction, the research hypothesis is stated. For example: The decremental theory of aging led us to hypothesize that older workers in "speed" jobs perform less well and have more absences and more accidents than other workers have.

In the Discussion, the answer is linked to the hypothesis: Our findings do not support the hypothesis that older workers in speed jobs perform less well and have more absences and more accidents than other workers have. The older workers generally earned more, were absent less often, and had fewer accidents than younger workers had. Furthermore, we found no significant difference between...

Written by Ed Hull edhull@home.nl 


\section{EASE Ethics Checklist for Authors}

EXPLANATION: obligatory declarations applying to all manuscripts are printed in bold.

\section{Original or acceptable secondary publication}

$\square$ No part of this manuscript (MS) has been published, except for passages that are properly cited.

$\square$ An abstract/summary of this MS has been published

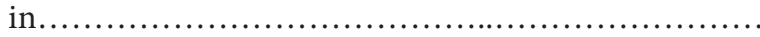

n.m.

This MS has already been published in

but in language. A full citation to the primary publication is included, and the copyright owner has agreed to its publication in English.

No part of this MS is currently being considered for publication elsewhere.

$\square$ In this MS, original data are clearly distinguished from published data. All information extracted from other publications is provided with citations.

\section{Authorship}

$\square$ All people listed as authors of this MS meet the authorship criteria, ie they contributed substantially to study planning, data collection or interpretation of results and wrote or critically revised the MS and approved its final submitted version and agree to be accountable for all aspects of the work (ICMJE 2017).

All people listed as authors of this MS are aware of it and have agreed to be listed.

$\square$ No person who meets the authorship criteria has been omitted.

\section{Ethical experimentation and interpretation}

$\square$ The study reported in this MS involved human participants and it meets the ethical principles of the Declaration of Helsinki (WMA 2013). Data have been disaggregated by sex (and, whenever possible, by race) and sex and gender considerations are properly addressed (see Sex and Gender Questions ${ }^{2}$ ).

$\square$ The study reported in this MS meets the Consensus Author Guidelines on Animal Ethics and Welfare for Veterinary Journals ${ }^{3}$ about humane treatment of animals and has been approved by an ethical review committee.

$\square$ The study reported in this MS meets other ethical principles, namely

$\square$ I and all the other authors of this MS did our best to avoid errors in experimental design, data presentation, interpretation, etc. However, if we discover any serious error in the MS (before or after publication), we will alert the editor promptly.

$\square$ None of our data presented in this MS has been fabricated or distorted, and no valid data have been excluded. Images shown in figures have not been manipulated to make a false impression on readers.

$\square$ Results of this study have been interpreted objectively. Any findings that run contrary to our point of view are discussed in the MS.

$\square$ The article does not, to the best of our knowledge, contain anything that is libellous, illegal, infringes anyone's copyright or other rights, or poses a threat to public safety.

\section{Acknowledgements}

$\square$ All sources of funding for the study reported in this MS are stated.

$\square$ All people who are not listed as authors but contributed considerably to the study reported in this MS or assisted in its writing (eg author's editors, translators, medical writers) are mentioned in the Acknowledgements.

$\square$ All people named in the Acknowledgements have agreed to this. However, they are not responsible for the final version of this MS.

$\square$ Consent has been obtained from the author(s) of unpublished data cited in the MS.

$\square$ Copyright owners of previously published figures or tables have agreed to their inclusion in this MS.

\section{Conflict of interest}

$\square$ All authors of this study have signed the EASE Form for Authors' Contributions and Conflict of Interest Disclosure ${ }^{4}$.

Date:.

Corresponding author:

MS title:

Compiled by Sylwia Ufnalska sylwia.ufnalska@gmail.com

\footnotetext{
${ }^{2}$ www.ease.org.uk/publications/sex-and-gender

${ }^{3}$ www.veteditors.org/consensus-author-guidelines-on-animalethics-and-welfare-for-editors/

${ }^{4}$ www.ease.org.uk/publications/ease-form
} 
Appendix: Plurals

\section{Examples of irregular plurals deriving from Latin or Greek}

\begin{tabular}{|c|c|c|}
\hline Singular & Plural & Examples \\
\hline$-a$ & $\begin{array}{l}-a e \\
\text { rarely -ata }\end{array}$ & $\begin{array}{l}\text { alga-algae, larva-larvae } \\
\text { stoma - stomata }\end{array}$ \\
\hline$-e x$ & -ices & $\begin{array}{l}\text { index - indices (or indexes } * \text { ) } \\
\text { apex-apices (or apexes } * \text { ) }\end{array}$ \\
\hline -ies & -ies & species, series, facies \\
\hline -is & -es & axis - axes, hypothesis - hypotheses \\
\hline$-i x$ & -ices & $\begin{array}{l}\text { appendix - appendices (or appendixes } * \text { ) } \\
\text { matrix - matrices (or matrixes } * \text { ) }\end{array}$ \\
\hline$-o n$ & $-a$ & $\begin{array}{l}\text { phenomenon - phenomena } \\
\text { criterion - criteria }\end{array}$ \\
\hline$-u m$ & $-a$ & datum-data**, bacterium - bacteria \\
\hline$-u s$ & $\begin{array}{l}-\boldsymbol{i} \\
\text { rarely -uses } \\
\text { or -era }\end{array}$ & $\begin{array}{l}\text { locus - loci, fungus - fungi (or funguses } *) \\
\text { sinus - sinuses } \\
\text { genus - genera }\end{array}$ \\
\hline
\end{tabular}

* Acceptable anglicized plurals that are also listed in dictionaries.

${ }^{* *}$ In non-scientific use, usually treated as a mass noun (like information, etc)

It must be remembered that some nouns used in everyday English also have irregular plural forms (eg woman women, foot - feet, tooth - teeth, mouse - mice, leaf - leaves, life - lives, tomato - tomatoes) or have no plural form (eg equipment, information, news). For more examples, see CSE (2014). If in doubt, consult a dictionary.

\section{Compiled by Sylwia Ufnalska} sylwia.ufnalska@gmail.com 


\section{Appendix: Simplicity}

\section{Examples of expressions that can be simplified or deleted $(\varnothing)$}

\begin{tabular}{|c|c|}
\hline Long or (sometimes) wrong & Better choice (often) \\
\hline accounted for by the fact that & because \\
\hline $\begin{array}{l}\text { as can be seen from Figure 1, substance } Z \\
\text { reduces twitching }\end{array}$ & substance $Z$ reduces twitching (Fig. 1) \\
\hline at the present moment & now \\
\hline bright yellow in colour & bright yellow \\
\hline conducted inoculation experiments on & inoculated \\
\hline considerable amount of & much \\
\hline despite the fact that & although \\
\hline due to the fact that & because \\
\hline for the reason that & because \\
\hline if conditions are such that & if \\
\hline in a considerable number of cases & often \\
\hline in view of the fact that & because \\
\hline it is of interest to note that & $\varnothing$ \\
\hline it may, however, be noted that & but \\
\hline large numbers of & many \\
\hline lazy in character & lazy \\
\hline methodology & methods \\
\hline owing to the fact that & because \\
\hline oval in shape & oval \\
\hline prior to & before \\
\hline taken into consideration & considered \\
\hline terminate & end \\
\hline the test in question & this test \\
\hline there can be little doubt that this is & this is probably \\
\hline to an extent equal to that of $X$ & as much as $X$ \\
\hline utilize & use \\
\hline whether or not & whether \\
\hline
\end{tabular}




\section{Examples of differences between British and American spelling}

\begin{tabular}{|c|c|}
\hline British English & American English \\
\hline $\begin{array}{c}-\boldsymbol{a e}- \\
\text { eg aetiology, faeces, haematology }\end{array}$ & $\begin{array}{c}-\boldsymbol{e}- \\
\text { eg etiology, feces, hematology }\end{array}$ \\
\hline $\begin{array}{l}\text {-ce in nouns, }-\boldsymbol{s e} \text { in verbs } \\
\text { eg defence, licence/license, practice/practise }\end{array}$ & $\begin{array}{l}\text {-se in nouns and verbs } \\
\text { eg defense, license } \\
\text { (but practice as both noun and verb) }\end{array}$ \\
\hline $\begin{array}{c}\text {-ise } \text { or }- \text { ize } \\
\text { eg organise/organize }\end{array}$ & $\begin{array}{c}\text {-ize } \\
\text { eg organize }\end{array}$ \\
\hline $\begin{array}{c}\text {-isation or -ization } \\
\text { eg organisation/organization }\end{array}$ & $\begin{array}{c}\text {-ization } \\
\text { eg organization } \\
\end{array}$ \\
\hline $\begin{array}{l}\text {-lled, -lling, -llor, etc. } \\
\text { eg labelled, travelling, councillor } \\
\text { (but fulfil, skilful) }\end{array}$ & $\begin{array}{l}\text {-led, -ling, -lor, etc. } \\
\text { eg labeled, traveling, councilor } \\
\text { (but fulfill, skillful) }\end{array}$ \\
\hline $\begin{array}{c}-\boldsymbol{o e}- \\
\text { eg diarrhoea, foetus, oestrogen }\end{array}$ & $\begin{array}{c}-\boldsymbol{e}- \\
\text { eg diarrhea, fetus, estrogen }\end{array}$ \\
\hline $\begin{array}{c}\text {-ogue } \\
\text { eg analogue, catalogue }\end{array}$ & $\begin{array}{c}-o g \text { or -ogue } \\
\text { eg analog/analogue, catalog/catalogue }\end{array}$ \\
\hline $\begin{array}{c}\text {-our } \\
\text { eg colour, behaviour, favour }\end{array}$ & $\begin{array}{c}-o r \\
\text { eg color, behavior, favor }\end{array}$ \\
\hline $\begin{array}{c}\text {-re } \\
\text { eg centre, fibre, metre, litre } \\
\text { (but meter for a measuring instrument) }\end{array}$ & $\begin{array}{c}-e r \\
\text { eg center, fiber, meter, liter }\end{array}$ \\
\hline $\begin{array}{c}\text {-yse } \\
\text { eg analyse, dialyse }\end{array}$ & $\begin{array}{c}\text {-yze } \\
\text { eg analyze, dialyze }\end{array}$ \\
\hline aluminium & aluminum or aluminium ${ }^{\star *}$ \\
\hline grey & gray \\
\hline mould & mold \\
\hline programme (general) or program (computer) & program \\
\hline sulphur or sulfur ${ }^{* *}$ & sulfur \\
\hline
\end{tabular}

${ }^{\star}$ One ending should be used consistently.

${ }^{\star *}$ Recommended by the International Union of Pure and Applied Chemistry and the Royal Society of Chemistry.

For more examples, see CSE (2014). If in doubt, consult a dictionary. Obviously, American and British English slightly differ not only in spelling but also in word use, grammar, punctuation, etc. However, those differences are outside the scope of this document.
Compiled by Sylwia Ufnalska sylwia.ufnalska@gmail.com 


\section{Text-tables - effective tools for presentation of small data sets}

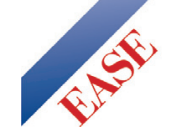

Arranging statistical information in a classic table and referring to it elsewhere means that readers do not access the information as immediately as they would when reading about it within the sentence. They have to find the table in the document (which may be on another page), losing some time. This slightly decreases the strength of the information. Quicker access to the information can be achieved within a sentence, but this is not an effective structure if more than 2 numbers are to be compared. In such situations, a "text-table" appears to be ideal for communicating information to the reader quickly and comprehensibly (Tufte 2001). The texttable is a simple table with no graphic elements, such as grid lines, rules, shading, or boxes. The text-table is embedded within a sentence, so no reference to it is needed. Keeping the power of tabular arrangements, text-tables immediately convey the message. Look at the following examples.

\section{Original sentence:}

Iron concentration means ( \pm standard deviation) were as follows: $11.2 \pm 0.3 \mathrm{mg} / \mathrm{dm}^{3}$ in sample $\mathrm{A}, 12.3 \pm 0.2 \mathrm{mg} / \mathrm{dm}^{3}$ in sample $B$, and $11.4 \pm 0.9 \mathrm{mg} / \mathrm{dm}^{3}$ in sample C.

\section{Modified:}

Iron concentration means ( \pm standard deviation, in $\mathrm{mg} /$ $\mathrm{dm}^{3}$ ) were as follows:

$$
\begin{array}{ll}
\text { sample B } & 12.3 \pm 0.2 \\
\text { sample C } & 11.4 \pm 0.9 \\
\text { sample A } & 11.2 \pm 0.3
\end{array}
$$

\section{Original sentence}

After the treatment was introduced, mortality tended to decline among patients aged 20-39 y (relative reduction $[\mathrm{RR}]=0.86 / \mathrm{y} ; 95 \%$ CI $0.81-0.92 ; P<0.001), 40$ to $59 \mathrm{y}$ of age $(\mathrm{RR}=0.97 / \mathrm{y} ; 95 \% \mathrm{CI} 0.92-1.03 ; P=0.24)$ and 60 to 79 y of age $(\mathrm{RR}=0.92 / \mathrm{y} ; 95 \%$ CI $0.86-0.99 ; P=0.06)$.

\section{Modified:}

After the treatment was introduced, mortality tended to decline among patients in all age groups (RR stands for relative reduction per year):
20-39y RR $=0.86 \quad$ (95\% CI 0.81-0.92; $P<0.001)$
$40-59$ y $\mathrm{RR}=0.97 \quad(95 \%$ CI $0.92-1.03 ; P=0.24)$
$60-79$ y RR $=0.92 \quad(95 \%$ CI $0.86-0.99 ; P=0.06)$

\section{Some rules for arranging text-tables}

1. The larger a text-table is, the less power it has.

2. The sentence that precedes the text-table acts as a heading that introduces the information the text-table represents, and usually ends with a colon. Text-tables should have neither headings nor footnotes.

3. Indentation of text-tables should fit the document's layout.

4. Occasional changes in font (such as italics, bold, a different typeface) may be used, but with caution. They can, however, put some emphasis on the tabular part.

5. Do not use too many text-tables in one document or on one page.

6. In addition to the above rules, apply rules for formatting regular tables. For example, numbers should be given in 2-3 effective digits; ordering rows by size and their correct alignment will facilitate reading and comparison of values; space between columns should be neither too wide nor too narrow.

Written by Marcin Kozak nyggus@gmail.com (for more information, see Kozak 2009)

\section{Practical tips for junior researchers}

- Consider publishing a review article once you have completed the first year of your PhD studies because: (1) you should already have a clear picture of the field and an up-to-date stock of references in your computer; (2) research results sometimes take a long time to get (in agronomy: 3 years of field experiments...); (3) journals love review articles (they tend to improve the impact factor); (4) the rejection rate of review articles is low (although some journals publish solicited reviews only, so you might want to contact the Editor first); (5) the non-specialist reader - such as a future employer - will understand a review article more easily than an original article with detailed results.

- Alternatively, publish meta-analyses or other databasebased research articles.
- Each part/item of an article should preferably be "almost" understandable (and citable) without reading other parts. The average time spent reading an article is falling, so virtually no one reads from Title to References. This phenomenon is amplified by the "digital explosion", whereby search engines identify individual items, such as abstracts or figures, rather than intact articles.

Written by Eric Lichtfouse eric.lichtfouse@dijon.inra.fr

For more advice, see EASE Toolkit for Authors

(www.ease.org.uk/publications/ease-toolkit-authors) 


\section{Background information about EASE and the EASE Guidelines}

The European Association of Science Editors (EASE) was formed in May 1982 at Pau, France, from the European Life Science Editors' Association (ELSE) and the European Association of Earth Science Editors (Editerra). Thus in 2012 we celebrated the $30^{\text {th }}$ anniversary of our Association.

EASE is affiliated to the International Union of Biological Sciences (IUBS), the International Union of Geological Sciences (IUGS), the International Organization for Standardization (ISO). Through its affiliation to IUBS and IUGS, our Association is also affiliated to the International Council for Science (ICSU) and is thereby in formal associate relations with UNESCO.

EASE cooperates with the International Society for Addiction Journal Editors (ISAJE), International Association of Veterinary Editors (IAVE), International Society of Managing and Technical Editors (ISMTE), the Council of Science Editors (CSE), and the Association of Earth Science Editors (AESE) in North America. Our other links include the African Association of Science Editors (AASE), the Association of Learned and Professional Society Publishers (ALPSP), the European Medical Writers Association (EMWA), Mediterranean Editors and Translators (MET), the Society of English-Native-Speaking Editors (Netherlands) (SENSE), and the Society for Editors and Proofreaders (SfEP).

We have major conferences every 2-3 years in various countries. EASE also organizes occasional seminars, courses, and other events between the conferences.

Since 1986, we publish a journal, now entitled European Science Editing. It is distributed to all members 4 times a year. It covers all aspects of editing and includes original articles and meeting reports, announces new developments and forthcoming events, reviews books, software and online resources, and highlights publications of interest to members. To facilitate the exchange of ideas between members, we also use an electronic EASE Forum, the EASE Journal Blog, and our website (www.ease.org.uk).

In 2007, we issued the EASE statement on inappropriate use of impact factors. Its major objective was to recommend that "journal impact factors are used only - and cautiously - for measuring and comparing the influence of entire journals, but not for the assessment of single papers, and certainly not for the assessment of researchers or research programmes either directly or as a surrogate".

In 2010, we published EASE Guidelines for Authors and Translators of Scientific Articles. Our goal was to make international scientific communication more efficient and help prevent scientific misconduct. This document is a set of generalized editorial recommendations concerning scientific articles to be published in English. We believe that if authors and translators follow these recommendations before submission, their manuscripts will be more likely to be accepted for publication. Moreover, the editorial process will probably be faster, so authors, translators, reviewers and editors will then save time.

EASE Guidelines are a result of long discussions on the EASE Forum and during our 2009 conference in Pisa, followed by consultations within the Council. The document is updated annually and is already available in 28 languages: Arabic, Bangla, Bosnian, Bulgarian, Chinese, Croatian, Czech, Dutch, English, Estonian, Finnish, French, German, Hungarian, Indonesian, Italian, Japanese, Korean, Persian, Polish, Portuguese (Brazilian), Romanian, Russian, Serbian, Slovenian, Spanish, Turkish, and Vietnamese. The English original and its translations can be freely downloaded as PDFs from our website. We invite volunteers to translate the document into other languages.

Many institutions promote EASE Guidelines (eg see the European Commission Research \& Innovation website), and many articles about this document have been published. Scientific journals also help in its popularization, by adding at the beginning of their instructions for authors a formula like:

Before submission, follow EASE Guidelines for Authors and Translators, freely available at www.ease.org.uk/ publications/author-guidelines in many languages. Adherence should increase the chances of acceptance of submitted manuscripts.

In 2012 we launched the EASE Toolkit for Authors, freely available on our website. The Toolkit supplements EASE Guidelines and includes more detailed recommendations and resources on scientific writing and publishing for less experienced researchers. In the same year, the EASE Gender Policy Committee was established to develop a set of guidelines for reporting of Sex and Gender Equity in Research (SAGER). Besides, EASE participated in the sTANDEM project (www.standem.eu), concerning standardized tests of professional English for healthcare professionals worldwide. Our Association also supports the campaign AllTrials (www.alltrials.net).

For more information about our Association, member's benefits, and major conferences, see the next page and our website. 




\section{Skills - communication - fellowship}

EASE is an internationally oriented community of individuals from diverse backgrounds, linguistic traditions, and professional experience, who share an interest in science communication and editing. Our Association offers the opportunity to stay abreast of trends in the rapidly changing environment of scientific publishing, whether traditional or electronic. As an EASE member, you can sharpen your editing, writing and thinking skills; broaden your outlook through encounters with people of different backgrounds and experience, or deepen your understanding of significant issues and specific working tools. Finally, in EASE we have fun and enjoy learning from each other while upholding the highest standards

\section{EASE membership offers the following benefits}

- A quarterly journal, European Science Editing, featuring articles related to science and editing, book and web reviews, regional and country news, and resources

- A major conference every 2 years

- Seminars and workshops on topics in science editing

- Science Editors' Handbook, (free online access, discount on printed version) covering all aspects of journal editing from on-screen editing to office management, peer review, and dealing with the media

- Advertising of your courses or services free of charge on the EASE website

- Discounts on job advertisements on the EASE website

- Opportunities to share problems and solutions with international colleagues from many disciplines (also on the EASE forum and ESE journal blog)

- Good networking and contacts for freelancers

- Discounts on editorial software, courses, etc.

\section{Our members}

EASE welcomes members from every corner of the world. They can be found in about 50 countries: from Australia to Venezuela by way of China, Russia and many more. EASE membership cuts across many disciplines and professions. Members work as commissioning editors, academics, translators, publishers, web and multi-media staff, indexers, graphic designers, statistical editors, science and technical writers, author's editors, journalists, proofreaders, and production personnel.

\section{Major conferences}

\author{
2018 Bucharest, Romania \\ 2016 Strasbourg, France \\ 2014 Split, Croatia \\ 2012 Tallinn, Estonia (30th Anniversary) \\ 2009 Pisa, Italy \\ 2006 Kraków, Poland \\ 2003 Bath, UK \\ 2003 Halifax, Nova Scotia, Canada \\ (joint meeting with AESE) \\ 2000 Tours, France
}

\author{
1998 Washington, DC, USA (joint meeting \\ with CBE and AESE) \\ 1997 Helsinki, Finland \\ 1994 Budapest, Hungary \\ 1991 Oxford, UK \\ 1989 Ottawa, Canada (joint meeting with \\ CBE and AESE) \\ 1988 Basel, Switzerland \\ 1985 Holmenkollen, Norway \\ 1984 Cambridge, UK \\ 1982 Pau, France
}

